\title{
Manufacturing High Quality Medical Catheters: A Technology Mastered by Few
}

\author{
Ali Hassan Zahraee ${ }^{1, \bowtie}$
}

Received: 08 December 2019 / Accepted: 15 December 2019 / Published Online: 15 December 2019

(C) SAMI Publishing Company (SPC) 2019

Medical catheters come in a variety of sizes for various applications. From Foley catheter, a flexible tube that a clinician passes through the urethra and into the bladder to drain urine, to coronary stent, a tube-shaped device placed in the coronary arteries that supply blood to the heart, to keep the arteries open in the treatment of coronary heart disease, they address medical conditions in different fields, from urology to cardiology, gastroenterology, and more.

Medical catheters are manufactured by medical device companies around the world. Nowadays, there are manufacturers in India, China, and Pakistan who can supply the global market with these devices. Yet, in many specific cases, their global market share is limited compared to the market share of manufacturers in Europe and the United States, despite a significant difference in prices. That is, some catheters made in the U.S., Germany, or France are much more in demand by clinicians, despite their prices being several fold the price of similar catheters made in India, or China, and this is not only in rich industrial countries. The same thing is true in many developing countries, where health care budgets are tight.

\footnotetext{
Corresponding author.

E-mail address: ahzahraee@gmail.com (A.H. Zahraee)
}

The reason is the superior quality of catheters made by well-known Western brands. But where does the difference in quality come from? In many of these catheters, the designs by different manufacturers are so close, that they can hardly be distinguished from one another. Basic materials, and methods used in their manufacturing is also the same. Yet, they show their difference when applied by clinicians. Specifically, this happens with catheters used under ultrasound guidance.

In many applications, the clinician needs to follow the path that the catheter takes to enter the patient's body. To do this, an ultrasound imaging equipment is used. Ultrasound imaging, also called sonography, ultrasonography, or echography, is a safe, and cost effective technique to visualize internal organs. When used during a clinical operation, it is called interventional echography, and allows the clinician to see the internal field of operation while performing an operation [1-3]. Echography works based on the principle that ultrasound waves travel through different mediums with different speeds, and when they reach the boundary between 2 mediums, a fraction of them pass and the rest is reflected.

\footnotetext{
${ }^{1}$ Biomedical Engineering Department, School of Advanced Technologies in Medicine, Medical Devices Technology Skills Lab, Isfahan University of Medical Sciences, Isfahan, Iran
} 
They travel fast through liquids, but most of them bounce back when they reach air, through which they travel much slower.

The difference in the quality of catheters from different manufacturers, from the clinician's point of view, comes from their visibility under echography [4-6]. The difference, from a manufacturing point of view, comes from the quality of the coating applied on the catheter.

Research on developing coating materials and methods that improve visibility of catheters, and needles under ultrasonography dates back to the nineties [7], and the subject has been actively researched, leading to significant success in technology transfer. There are now companies that provide coating services specifically for medical devices that need to be visualized under sonography. However, the technology remains in the hands of a few companies in industrial countries; needs to be achieved and matured

\section{References}

1. M.A.L. Bell, J. Shubert; Photoacoustic-based visual servoing of a needle tip. Sci. Reports 8 (2018) 15519.

2. D. Souza, I. Lerman, T.M. Halaszynski; Ultrasound technical aspects: How to improve needle visibility. Atlas of Ultrasound-Guided Procedures in Interventional Pain Management. Springer, New York, NY, 2018, 27-55.

3. J. Yang, E. Ward, T.W. Sung, J. Wang, C. Barback, N. Mendez, S. Blair, W.C. Trogler, A.C. Kummel; Silica shells/adhesive composite film for color doppler ultrasound guided needle placement. ACS Biomat. Sci. Eng. 3 (2017) 1780-1787.

4. P. Beigi, R. Rohling, T. Salcudean, V.A. Lessoway, G.C. Ng; Needle trajectory and tip through research. The problem can be decomposed into two main subproblems:

- How to make a coating material that can be applied on the surface of different substrates used in the manufacturing of polymer or metallic medical devices. The material needs to be biocompatible, and must resist different sterilization methods such as sterilization by gamma radiation or ethylene oxide exposure.

- How to develop a large scale production line for this coating method. The production volume of medical catheters, or needles is typically in the order of thousands per day.

Solving these challenges will lead to higher quality, and thus higher market share for manufacturers of medical catheters in developing countries, and needles by allowing them to compete with wellknown Western brands.

localization in real-time 3-D ultrasound using a moving stylus. Ultrasound Med. Biol. 41 (2015) 2057-2070.

5. F.W. Abdallah, A.J. Macfarlane, R. Brull; The requisites of needle-to-nerve proximity for ultrasound-guided regional anesthesia: A scoping review of the evidence. Reg. Anesth. Pain Med. 41 (2016) 221-228.

6. G. Reusz, P. Sarkany, J. Gal, A. Csomos; Needle-related ultrasound artifacts and their importance in anaesthetic practice. Brit. J. Anaesth.112 (2014)794-802.

7. R.H. Gottlieb, W.B. Robinette, D.J. Rubens, D.F. Hartley, P.J. Fultz, M.R. Violante; Coating agent permits improved visualization of biopsy needles during sonography. Am. J. Roentgenol. 171 (1998) 1301-1302. 